\title{
IMPACTO DO MANEJO DOS RESÍDUOS DA COLHEITA, DO PREPARO DO SOLO E DA ADUBAÇÃO NA PRODUTIVIDADE DE EUCALIPTO ${ }^{(1)}$
}

\author{
Frederico Alfenas Silva Valente Paes ${ }^{(2)}$, Augusto Miguel Nascimento Lima ${ }^{(3)}$, Rodrigo Eiji \\ Hakamada $^{(4)}$ \& Nairam Félix de Barros ${ }^{(5)}$
}

\begin{abstract}
RESUMO
Tem sido cada vez maior a preocupação das empresas do setor florestal em adotar práticas pautadas na conservação do solo e da água. Nesse sentido, este trabalho teve por objetivo avaliar o impacto do manejo dos resíduos da colheita, do preparo do solo e do uso de resíduos industriais, na fertilidade do solo e produtividade de eucalipto. $O$ experimento foi iniciado após o corte raso de um plantio comercial de Eucalyptus grandis, onde os resíduos da colheita foram manejados (retirada de todo o resíduo; remoção da casca e dos galhos com diâmetro superior a 3,0 cm; e manutenção de todos os resíduos na superfície do solo). Em seguida, realizaram-se o preparo do solo (com subsolador de uma e três hastes), a aplicação dos resíduos industriais (resíduo de celulose e cinzas) na superfície do solo e o plantio de mudas de Eucalyptus grandis $x$ E. urophylla. Foi utilizado o delineamento em blocos ao acaso, contendo oito tratamentos e quatro repetições. Os tratamentos consistiram da combinação dos diferentes tipos de manejo dos resíduos da colheita, preparo do solo e aplicação dos resíduos industriais. Cada parcela experimental foi composta por cinco linhas com 19 plantas cada. Aos 83 meses após o plantio, foram medidos o DAP (diâmetro à altura do peito) e a altura das árvores, para cálculo do volume de madeira. A fertilização e a manutenção dos resíduos da colheita florestal elevaram os teores de $\mathrm{Ca}^{2+} \mathbf{e} \mathbf{M g}^{2+}$ trocáveis no solo. A manutenção total dos resíduos vegetais na área após a colheita resultou em aumento de $71,7 \mathrm{~m}^{3} \mathrm{ha}^{-1}$ de madeira, quando comparado à remoção de todos os resíduos. Não houve diferença entre os modos de preparo do solo com subsolador de uma e três hastes, quanto ao volume de madeira. Os maiores volumes de madeira foram obtidos dos tratamentos que receberam as maiores quantidades de resíduo de celulose e
\end{abstract}

\footnotetext{
(1) Recebido para publicação em $1^{\circ}$ de junho de 2012 e aprovado em 17 de abril de 2013.

(2) Engenheiro Florestal. Rua Joaquim Francisco da Silveira, 305. CEP 31160-200 Belo Horizonte (MG). E-mail: fredericoalfenas@gmail.com

(3) Professor da Universidade Federal do Vale do São Francisco. Av. José de Sá Maniçoba, s/n. CEP 56304-917 Petrolina (PE). E-mail: augusto.lima@univasf.edu.br

(4) Pesquisador Florestal. Rodovia SP 340, km 171. CEP 13840-970 Mogi Guaçu (SP). E-mail: rodrigo_hakamada@yahoo.com.br

(5) Professor do Departamento de Solos, UFV. Av. P.H. Rolfs, s/n. CEP 36570-000 Viçosa (MG). E-mail: nfbarros@ufv.br
} 
cinzas, ao mesmo tempo em que foi mantida parte do resíduo vegetal após a colheita. A aplicação do resíduo de celulose e cinzas favoreceu a manutenção e, ou, aumento da produtividade do eucalipto. Termos de indexação: manejo e conservação dos solos, sustentabilidade e gestão
de resíduos.

\title{
SUMMARY: EFFECT OF HARVEST RESIDUES MANAGEMENT, SOIL TILLAGE AND FERTILIZATION ON EUCALYPTUS PRODUCTIVITY
}

\begin{abstract}
Forestry companies have become increasingly concerned about the adoption of practices based on the conservation of soil and water. Thus, this study aimed to assess the impact of crop residue management, tillage and the use of industrial wastes on soil fertility and productivity of eucalyptus. The experiment started after clear-cutting of a commercial plantation of Eucalyptus grandis and the harvest residues were managed differently (removal of all residues; removal of bark and branches with diameter $>3.0 \mathrm{~cm}$; and maintenance of all residues on the soil surface). Thereafter, the soil was tilled (with a subsoiler with one or three shanks), industrial waste was applied (pulp residue and ash) on the soil surface and seedlings of Eucalyptus grandis x E. urophylla planted. A randomized block design was used with eight treatments and four replications. The treatments consisted of combinations of different types of crop residue management, soil tillage and application of industrial waste. Each experimental plot consisted of five rows each with 19 trees. Eighty-three months after planting, the DBH (diameter at breast height) and tree height were measured to calculate the wood volume. Fertilization and maintenance of forestry crop residues raised the levels of exchangeable $\mathrm{Ca}^{2+}$ and $\mathrm{Mg}^{2+}$ in the soil. The maintenance of all plant residues in the field after harvesting induced an increase of $71.7 \mathrm{~m}^{3} \mathrm{ha}^{-1}$ compared to the treatment with removal of all waste. There was no difference between the subsoiler tillage systems with one or three shanks on the wood volume. Highest timber volumes were obtained in the treatments in which the largest quantities of cellulose and ash residue were applied while part of the plant waste was left on the soil surface after harvest. The application of wood and ash residues maintained and/or increased Eucalyptus productivity.
\end{abstract}

Index terms: soil management and conservation, sustainability and waste management.

\section{INTRODUÇÃO}

A preocupação das empresas do setor florestal em adotar práticas pautadas na conservação do solo e da água tem sido cada vez maior, principalmente na região tropical, em razão da baixa fertilidade natural dos solos (Novais \& Smyth, 1999).

De todas as práticas silviculturais realizadas durante o ciclo de produção de madeira, a colheita florestal é considerada a operação mais impactante em termos de prejuízos ao talhão, sendo agravada pelas rotações mais curtas e pela exportação de nutrientes (Bellote et al., 2008). Se a remoção de nutrientes resultante do processo de exploração florestal for superior às entradas de nutrientes no talhão, o balanço nutricional do sistema solo-planta será negativo, reduzindo o potencial produtivo da área. Leite et al. (2010), ao estudarem as alterações de propriedades químicas de solos cultivados com eucalipto em cinco regiões no Vale do Rio Doce, MG, apresentaram que, para manter e melhorar as propriedades químicas do solo, o balanço de nutrientes deve ser estritamente controlado, o que requer eficiente gestão dos resíduos da colheita, da adubação e da calagem.
Segundo Santana et al. (2008), o conteúdo estimado de nutrientes acumulados na copa e na casca do eucalipto representa, em média, 65, 70, 64, 79 e 79\% de N, P, K, Ca e Mg, respectivamente, até 6,5 anos de idade. Dessa forma, a manutenção dos resíduos decorrentes da colheita florestal, notadamente folhas, galhos, ponteiras e casca, é importante prática para reduzir o prejuízo do solo, causado pela exploração florestal. No caso da colheita de "toras-longas", que envolvem o corte e desgalhamento das árvores no local de abate (o transporte dessas e o posterior processamento na margem da estrada ou no pátio), o descascamento não é feito no campo, proporcionando a exportação dos nutrientes contidos na casca. Nesse sentido, as doses de fertilizantes devem ser ainda maiores para repor os nutrientes exportados.

Uma das alternativas para repor os nutrientes exportados é a aplicação de resíduos gerados pelo processo de produção de celulose, juntamente com as cinzas provenientes de caldeira de biomassa florestal. Esses materiais quando utilizados em quantidades adequadas contribuem para manter a capacidade produtiva do sítio (Hakamada et al., 2009). De acordo com Bellote et al. (1998), a aplicação conjunta de 
fertilizantes minerais e de resíduos provenientes da indústria de celulose proporcionou incrementos da produção da ordem de 65 a $85 \%$ em plantios de Eucalyptus grandis com três anos de idade, em comparação com a adubação mineral. Hakamada et al. (2009) observaram que a aplicação contínua de resíduos celulósicos resultou em alterações significativas no teor de $\mathrm{Ca}^{2+}$ do solo, que passou de 0,31 para $0,50 \mathrm{cmol}_{\mathrm{c}} \mathrm{dm}^{-3}$; na acidez potencial $(\mathrm{H}+\mathrm{Al})$, que reduziu de 4,50 para $3,73 \mathrm{cmol}_{\mathrm{c}} \mathrm{dm}^{-3}$; e no teor de $\mathrm{Na}^{+}$, que se elevou de 0,03 para $0,1 \mathrm{cmol}_{\mathrm{c}} \mathrm{dm}^{-3}$, ressaltando a importância da realização de mais estudos que venham a comprovar o impacto desse material no solo ao longo do tempo.

O preparo do solo, nos moldes do cultivo mínimo, é também uma técnica que pode contribuir para o aumento da produtividade florestal. Nesse modo de preparo, a maior parte dos resíduos culturais é mantida sobre a superfície do solo. Dentre as suas principais vantagens destacam-se: a manutenção prolongada do resíduo orgânico na superfície do solo, protegendo-o do impacto direto das gotas de chuva e atenuando a velocidade da água superficial; a conservação da umidade do solo na superfície; a melhoria da micro e da mesofauna do solo; e a melhoria da fertilidade e das propriedades físicas do solo (Sanches et al., 1995). Em meio às diversas opções para se realizar o preparo do solo, de acordo com Dedecek et al. (2007), a subsolagem na linha de plantio se consolidou na área florestal em razão dos seus efeitos benéficos para as plantas e das suas vantagens operacionais (maior capacidade de trabalho) e econômicas (menor custo).

Nesse contexto, este trabalho teve por objetivo avaliar o impacto de diferentes manejos dos resíduos da colheita florestal, de dois modos de preparo do solo e de distintas adubações de plantio, incluindo a utilização de resíduo celulósico e cinzas de madeira, na fertilidade do solo e produtividade de um povoamento de eucalipto, em segundo ciclo.

\section{MATERIAL E MÉTODOS}

\section{Caracterização da área em estudo}

O experimento está localizado na região nordeste do Estado de São Paulo, no município de Mogi Guaçu $\left(22^{\circ} 08^{\prime} \mathrm{S}\right.$ e $48^{\circ} 05^{\prime} \mathrm{W}$ e altitude de $\left.660 \mathrm{~m}\right)$, sendo instalado em setembro de 1998, logo após o corte raso do primeiro ciclo de um plantio de Eucalyptus grandis Hill ex Maiden, com 12 anos de idade. O clima da região, segundo a classificação de Köppen, é Cwa (temperado chuvoso mesotérmico). A temperatura média anual do local é de $21^{\circ} \mathrm{C}$; a precipitação pluvial média anual de $1.350 \mathrm{~mm}$, concentrando-se entre os meses de outubro e março; e o déficit hídrico, de $36 \mathrm{~mm}$. O solo é classificado como Latossolo Vermelho-Amarelo distrófico típico, textura média e relevo plano (Embrapa, 1999).
Antes da colheita do povoamento, foram coletadas amostras de solo distantes $0,5 \mathrm{~m}$ da linha de plantio na camada de 0-30 cm; cada amostra de solo era composta por três subamostras. Após a coleta, essas amostras foram submetidas à determinação do $\mathrm{pH}$, dos teores de $\mathrm{P}, \mathrm{Ca}^{2+}, \mathrm{Mg}^{2+}, \mathrm{K}^{+}, \mathrm{Al}^{3+}, \mathrm{H}+\mathrm{Al}$ e C orgânico total, segundo procedimento proposto por Claessen et al. (1997) e adaptado de Dedecek et al. (2007). Também foram determinados os teores de areia, silte e argila (Quadro 1).

A colheita foi realizada mecanicamente, utilizandose o método de "toras longas", por meio do FellerBuncher, Skidder e Garra-traçadora.

Neste trabalho, relatam-se os resultados aos 83 meses de idade; os obtidos na idade de 48 meses foram publicados por Dedecek et al. (2007).

\section{Manejo dos resíduos da colheita, preparo do solo e adubação}

Após a colheita, os resíduos foram manejados e, em seguida, realizaram-se o preparo do solo e a adubação de plantio, conforme descritos no quadro 2 .

Três diferentes manejos foram aplicados aos resíduos da colheita: retirada de todo o resíduo (galhos, folhas, ponteiras, casca e serapilheira); remoção da casca e dos galhos, com diâmetro superior a $3,0 \mathrm{~cm}$; e manutenção de todos os resíduos na superfície do solo. No quadro 3, é apresentado o conteúdo de nutrientes dos resíduos (Bellote et al., 2008). Onde houve a remoção da casca e dos galhos com diâmetro superior a $3,0 \mathrm{~cm}$, as folhas e os galhos com diâmetro inferior a 3,0 cm foram mantidos na superfície do solo.

O preparo do solo foi realizado por meio da subsolagem, a 0,4 $\mathrm{m}$ de profundidade na linha de plantio. Foram utilizados dois tipos de subsoladores, com uma ou três hastes, espaçadas entre si em 1,0 m.

Em relação à adubação, os fertilizantes minerais sulfato de amônio, superfosfato simples e cloreto de potássio sob a formulação N-P-K (6-26-13) foram aplicados em filete contínuo na linha de plantio a uma profundidade de $0,1 \mathrm{~m}$, enquanto o resíduo de celulose e as cinzas de caldeira de biomassa florestal foram uniformemente distribuídos na superfície do solo, antes do plantio das mudas de eucalipto. As análises químicas desses resíduos são apresentadas no quadro 4.

O experimento foi mantido livre de plantas daninhas até o fechamento das copas das árvores, utilizando-se herbicidas em pré-emergência (Isoxaflutole) e em pós-emergência (Glyphosate). Não foram realizadas adubações de cobertura em nenhum dos tratamentos, apenas a adubação de plantio (Quadro 2).

Quando o povoamento de eucalipto completou 83 meses de idade, foram coletadas amostras de solo distantes $0,5 \mathrm{~m}$ da linha de plantio, na camada de 0 $30 \mathrm{~cm}$; cada amostra de solo era composta por três subamostras. Após a coleta, essas amostras foram submetidas à determinação do $\mathrm{pH}$, dos teores de $\mathrm{P}$, 
$\mathrm{Ca}^{2+}, \mathrm{Mg}^{2+}, \mathrm{K}^{+}, \mathrm{Al}^{3+}, \mathrm{H}+\mathrm{Al}$ e $\mathrm{C}$ orgânico total e granulometria, segundo procedimento proposto por Claessen et al. (1997) (Quadro 5). Ressalta-se que para as amostras obtidas nessa coleta, o teor de $\mathrm{P}$ disponível foi obtido pela resina de troca aniônica.

\section{Delineamento experimental}

Utilizou-se o delineamento em blocos ao acaso, com quatro repetições. Cada parcela experimental foi composta por cinco linhas com 19 plantas cada, sendo as mensurações feitas em 17 árvores de cada uma das três linhas centrais (bordadura simples). $\mathrm{O}$ espaçamento entrelinhas e entre plantas foi de $3 \mathrm{~m}$. $\mathrm{O}$ material genético empregado no plantio do segundo ciclo foi um híbrido de Eucalyptus grandis $x$ E. urophylla.

\section{Quantificação do volume de madeira produzido e amostragem do solo}

Quando o povoamento de eucalipto completou 83 meses de idade, foi medido diâmetro a altura do peito (DAP $=1,3 \mathrm{~m}$ da superfície do solo) e a altura total de todas as plantas da parcela útil. Além disso, foi realizada a amostragem de solo na camada de $0-0,30 \mathrm{~m}$ na linha de plantio central de cada parcela, para análises químicas, segundo Claessen et al. (1997).

Os dados de DAP e a altura total foram utilizados para determinar o volume de madeira com casca por árvore (Vcc/árvore), a partir da equação 1, que foi previamente ajustada para o material genético empregado no experimento.

Vcclárvore $\left(m^{3}\right)=e^{(-10,04951+1,863489+\text { Ln DAP }+1,043579+\text { LnAltura Total })}(1)$ em que:Vcc = volume de madeira com casca $\left(\mathrm{m}^{3}\right) ; \mathrm{DAP}$ = diâmetro à altura do peito $(\mathrm{cm})$; e Altura total = altura total da árvore (m).

O cálculo do volume total de madeira por hectare foi feito considerando o somatório do volume produzido por unidade experimental e extrapolado para uma população de 1.111 árvores por hectare. Os dados foram submetidos ao teste de homocedasticidade e normalidade e, em seguida, à análise de variância. Compararam-se as médias dos tratamentos pelo teste Tukey, a $5 \%$. Os resultados das análises químicas do solo, aos 83 meses após a instalação do experimento, foram submetidos à análise estatística descritiva. Correlacionaram-se os valores determinados com o volume médio de madeira produzido, adotando-se o

Quadro 1. Características químicas e físicas do solo, antes do início do experimento

\begin{tabular}{|c|c|c|c|c|c|c|c|c|c|c|c|c|c|}
\hline $\mathrm{pH}\left(\mathrm{CaCl}_{2}\right)$ & $\mathbf{P}^{(\mathbf{1})}$ & $\mathbf{C a}^{2+}$ & $\mathrm{Mg}^{2+}$ & $\mathbf{K}^{+}$ & $\mathbf{S B}^{(2)}$ & $\mathbf{A l}^{3+}$ & $\mathbf{H}+\mathbf{A l}$ & CTC $^{(3)}$ & $\operatorname{COT}^{(4)}$ & $\mathbf{A G}^{(5)}$ & $\mathbf{A F}^{(6)}$ & $\operatorname{Arg}^{(7)}$ & Silte \\
\hline & $\mathrm{mg} \mathrm{dm}{ }^{-3}$ & & & & $\mathrm{~mol}_{\mathrm{c}} \mathrm{dn}$ & & & & $\mathrm{g} \mathrm{dm}^{-3}$ & & $-\mathrm{g} \mathrm{l}$ & & \\
\hline 3,93 & 1,4 & 0,56 & 0,35 & 0,3 & 1,2 & - & 63,0 & 64,2 & 13,4 & 460 & 227 & 220 & 100 \\
\hline
\end{tabular}

(1) Extrator Mehlich-1; ${ }^{(2)}$ Soma de bases; ${ }^{(3)}$ Capacidade de troca catiônica; ${ }^{(4)}$ Carbono orgânico total; ${ }^{(5)}$ Areia grossa; ${ }^{(6)}$ Areia fina; $\mathrm{e}^{(7)}$ Argila. Fonte: Adaptado de Dedeceket al. (2007).

\section{Quadro 2. Descrição dos tratamentos}

\begin{tabular}{|c|c|}
\hline Trat. & Descrição \\
\hline 1 & $\begin{array}{l}\text { Todo resíduo da colheita retirado; preparo do solo com subsolador de três hastes; e adubação de plantio com } \\
200 \mathrm{~kg} \mathrm{ha}^{-1} \text { de N-P-K (06-26-13) }\end{array}$ \\
\hline 2 & $\begin{array}{l}\text { Todo resíduo da colheita mantido na área; preparo do solo com subsolador de três hastes; e adubação de } \\
\text { plantio com } 200 \mathrm{~kg} \mathrm{ha}^{-1} \mathrm{~N}-\mathrm{P}-\mathrm{K}(06-26-13)\end{array}$ \\
\hline 3 & $\begin{array}{l}\text { Remoção dos galhos >3 cm e da casca; preparo do solo com subsolador de três hastes; e adubação de plantio } \\
\text { com } 200 \mathrm{~kg} \mathrm{ha}^{-1} \mathrm{~N}-\mathrm{P}-\mathrm{K}(06-26-13)\end{array}$ \\
\hline 4 & $\begin{array}{l}\text { Remoção dos galhos >3 cm e da casca; preparo do solo com subsolador de três hastes; e adubação de plantio } \\
\text { com } 200 \mathrm{~kg} \mathrm{ha}^{-1} \mathrm{~N}-\mathrm{P}-\mathrm{K}(06-26-13)+7,5 \mathrm{Mg} \mathrm{ha}^{-1} \text { de resíduo de celulose }+2,0 \mathrm{Mg} \mathrm{ha}^{-1} \text { de cinzas }\end{array}$ \\
\hline 5 & $\begin{array}{l}\text { Remoção dos galhos >3 cm e da casca; preparo do solo com subsolador de uma haste; e adubação de plantio } \\
\text { com } 200 \mathrm{~kg} \mathrm{ha}^{-1} \mathrm{~N}-\mathrm{P}-\mathrm{K}(06-26-13)+7,5 \mathrm{Mg} \mathrm{ha}^{-1} \text { de resíduo de celulose }+2,0 \mathrm{Mg} \mathrm{ha}^{-1} \text { de cinzas }\end{array}$ \\
\hline 6 & $\begin{array}{l}\text { Remoção dos galhos >3 cm e da casca; preparo do solo com subsolador de três hastes; e adubação de plantio } \\
\text { com } 200 \mathrm{~kg} \mathrm{ha}^{-1} \mathrm{~N}-\mathrm{P}-\mathrm{K}(06-26-13)+15,0 \mathrm{Mg} \mathrm{ha}^{-1} \text { de resíduo de celulose }+4,0 \mathrm{Mg} \mathrm{ha}^{-1} \text { de cinzas }\end{array}$ \\
\hline 7 & $\begin{array}{l}\text { Remoção dos galhos >3 cm e da casca; preparo do solo com subsolador de uma haste; e adubação de plantio } \\
\text { com } 200 \mathrm{~kg} \mathrm{ha}^{-1} \mathrm{~N}-\mathrm{P}-\mathrm{K}(06-26-13)+15,0 \mathrm{Mg} \mathrm{ha}^{-1} \text { de resíduo de celulose }+4,0 \mathrm{Mg} \mathrm{ha}^{-1} \text { de cinzas }\end{array}$ \\
\hline 8 & $\begin{array}{l}\text { Todo resíduo da colheita retirado; preparo do solo com subsolador de três hastes; e adubação de plantio com } \\
200 \mathrm{~kg} \mathrm{ha}^{-1} \mathrm{~N}-\mathrm{P}-\mathrm{K}(06-26-13)+15,0 \mathrm{Mg} \mathrm{ha}^{-1} \text { de resíduo de celulose }+4,0 \mathrm{Mg} \mathrm{ha}^{-1} \text { de cinzas }\end{array}$ \\
\hline
\end{tabular}


Quadro 3. Quantidade de nutrientes presentes no resíduo das árvores, adubação NPK, resíduo industrial e conteúdo total de nutrientes aplicados por tratamento

\begin{tabular}{|c|c|c|c|c|c|}
\hline Trat. $^{(1)}$ & $\mathbf{N}$ & $\mathbf{P}$ & $\mathbf{K}$ & $\mathbf{C a}$ & Mg \\
\hline & & & $\mathrm{gg}$ ha & & \\
\hline \multicolumn{6}{|c|}{ Resíduo das árvores } \\
\hline 2 & 266 & 29 & 164 & 177 & 38 \\
\hline $3,4,5,6,7$ & 208 & 31 & 124 & 77 & 23 \\
\hline \multicolumn{6}{|c|}{ Adubação NPK } \\
\hline 1 a 8 & 16 & 23 & 22 & - & - \\
\hline \multicolumn{6}{|c|}{ Resíduo industrial (resíduo de celulose e cinzas de madeira } \\
\hline 4,5 & 29 & 6 & 14 & 154 & 10 \\
\hline $6,7,8$ & 58 & 12 & 28 & 308 & 20 \\
\hline \multicolumn{6}{|c|}{ Total de nutrientes adicionados por tratamento } \\
\hline 1 & 16 & 23 & 22 & & \\
\hline 2 & 282 & 52 & 186 & 177 & 38 \\
\hline 3 & 224 & 54 & 146 & 77 & 23 \\
\hline 4,5 & 253 & 60 & 160 & 231 & 33 \\
\hline 6,7 & 282 & 66 & 174 & 385 & 43 \\
\hline 8 & 74 & 35 & 50 & 308 & 20 \\
\hline
\end{tabular}

(1) 1: Todo resíduo da colheita retirado, preparo do solo com subsolador de três hastes, adubação de plantio com $200 \mathrm{~kg} \mathrm{ha}^{-1}$ de N-P-K (06-26-13); 2: Todo resíduo da colheita mantido na área, preparo do solo com subsolador de três hastes, adubação de plantio com $200 \mathrm{~kg} \mathrm{ha}^{-1}$ N-P-K (06-26-13); 3: Remoção dos galhos $>3 \mathrm{~cm}$ e da casca, preparo do solo com subsolador de três hastes, adubação de plantio com $200 \mathrm{~kg} \mathrm{ha}^{-1} \mathrm{~N}-\mathrm{P}-\mathrm{K}$ (06-2613); 4: Remoção dos galhos $>3 \mathrm{~cm}$ e da casca, preparo do solo com subsolador de três hastes, adubação de plantio com $200 \mathrm{~kg} \mathrm{ha}^{-1}$ N-P-K (06-26-13) + 7,5 $\mathrm{Mg} \mathrm{ha}^{-1}$ de resíduo de celulose $+2,0$ $\mathrm{Mg} \mathrm{ha}^{-1}$ de cinzas; 5 : Remoção dos galhos $>3 \mathrm{~cm}$ e da casca, preparo do solo com subsolador de uma haste, adubação de plantio com $200 \mathrm{~kg} \mathrm{ha}^{-1} \mathrm{~N}-\mathrm{P}-\mathrm{K}(06-26-13)+7,5 \mathrm{Mg} \mathrm{ha}^{-1} \mathrm{de}$ resíduo de celulose $+2,0 \mathrm{Mg} \mathrm{ha}^{-1}$ de cinzas; 6: Remoção dos galhos $>3 \mathrm{~cm}$ e da casca, preparo do solo com subsolador de três hastes, adubação de plantio com $200 \mathrm{~kg} \mathrm{ha}^{-1}$ N-P-K (06-2613) + 15,0 $\mathrm{Mg} \mathrm{ha}^{-1}$ de resíduo de celulose $+4,0 \mathrm{Mg} \mathrm{ha}^{-1} \mathrm{de}$ cinzas; 7: Remoção dos galhos $>3 \mathrm{~cm}$ e da casca, preparo do solo com subsolador de uma haste, adubação de plantio com $200 \mathrm{~kg} \mathrm{ha}^{-1}$ N-P-K $(06-26-13)+15,0 \mathrm{Mg} \mathrm{ha}^{-1}$ de resíduo de celulose $+4,0 \mathrm{Mg} \mathrm{ha}^{-1}$ de cinzas; e 8: Todo resíduo da colheita retirado, preparo do solo com subsolador de três hastes, adubação de plantio com $200 \mathrm{~kg} \mathrm{ha}^{-1} \mathrm{~N}-\mathrm{P}-\mathrm{K}(06-26-13)+15,0 \mathrm{Mg} \mathrm{ha}^{-1} \mathrm{de}$ resíduo de celulose $+4,0 \mathrm{Mg} \mathrm{ha}^{-1}$ de cinzas. Fonte: Adaptado de Bellote et al. (2008).

Quadro 4. Características dos resíduos industrial de celulose e cinzas de madeira adicionados ao solo

\begin{tabular}{lcc}
\hline \multirow{2}{*}{ Atributo } & \multicolumn{2}{c}{ Composição média } \\
\cline { 2 - 3 } & Cinza & Resíduo de celulose \\
\hline $\mathrm{pH}\left(\mathrm{CaCl}_{2}\right)$ & 8,80 & 7,50 \\
$\mathrm{~N}$ total $(\%)$ & 0,15 & 0,34 \\
$\mathrm{P}_{2} \mathrm{O}_{5}(\%)$ & 0,26 & 0,09 \\
$\mathrm{~K}_{2} \mathrm{O}(\%)$ & 0,54 & 0,07 \\
$\mathrm{Ca}$ total $(\%)$ & 1,84 & 1,55 \\
$\mathrm{Mg}$ total $(\%)$ & 0,16 & 0,09 \\
$\mathrm{C}: \mathrm{N}$ & $30: 1$ & $25: 1$ \\
\hline
\end{tabular}

Fonte: Adaptado de Bellote et al. (2008). nível de significância de $5 \%$. Para realização dessas análises, foi empregado o software "Statistica7.0" (Statsoft, 2008).

\section{RESULTADOS E DISCUSSÃO}

Os valores de $\mathrm{pH}$ nos diferentes tratamentos apresentaram-se em torno de 4,0 (Quadro 5), porém a cultura do eucalipto é tolerante à acidez do solo (Barros \& Novais, 1990; Paula et al., 2012). Valores de pH variando entre 5,6-6,0 são essenciais para aumentar a CTC efetiva do solo, resultando em menores perdas de cátions por lixiviação, além de não comprometer a disponibilidade de micronutrientes nele (Raij et al., 1996; Sousa et al., 2007). Os teores de P disponível no solo apresentam-se $\geq 7,5 \mathrm{mg} \mathrm{dm}^{-3}$, estando inseridos nas classes de interpretação média a alta disponibilidade, conforme exigência nutricional de culturas florestais (Raij et al., 1996). A adubação e o manejo do resíduo da colheita do eucalipto resultaram em elevação nos teores de $\mathrm{Ca}^{2+}$ e $\mathrm{Mg}^{2+}$ no solo (Quadro 4). A elevada concentração desses nutrientes no resíduo industrial (resíduo de celulose e cinzas de madeira) contribuiu para elevar os teores de $\mathrm{Ca}^{2+} \mathrm{e}$ $\mathrm{Mg}^{2+}$ no solo, sugerindo o uso dos resíduos da indústria de celulose como fonte alternativa desses nutrientes para as plantas (Dedecek et al., 2007). Apesar de a adubação e o manejo do resíduo da colheita contribuírem como fonte de $\mathrm{Ca}$ e $\mathrm{Mg}$ para as plantas, os teores desses nutrientes no solo estão abaixo do nível crítico de manutenção, $0,7 \mathrm{cmol}_{\mathrm{c}} \mathrm{dm}^{-3}$, para o $\mathrm{Ca}^{2+}$; e $0,16 \mathrm{cmol}_{\mathrm{c}} \mathrm{dm}^{-3}$, para $\mathrm{Mg}^{2+}$, considerando um incremento médio anual de $40 \mathrm{~m}^{3} \mathrm{ha}^{-1} \mathrm{ano}^{-1}$ (Barros \& Novais, 1999). Os teores de $\mathrm{K}^{+}$no solo estão abaixo do nível crítico de manutenção, $75 \mathrm{mg} \mathrm{dm}^{-3}$, considerando um incremento médio anual de $40 \mathrm{~m}^{3} \mathrm{ha}^{-1} \mathrm{ano}^{-1}$ (Barros \& Novais, 1999). Os teores de $\mathrm{Al}^{3+}$ são $\geq 7,9 \mathrm{mmol}_{\mathrm{c}} \mathrm{dm}^{-3}$; esses valores não são prejudiciais à cultura do eucalipto (Barros \& Novais, 1990). Os teores de COT estão inseridos na classe de média fertilidade para o carbono orgânico do solo (Ribeiro et al., 1999). Como o plantio de eucalipto neste trabalho encontrava-se com 83 meses de idade $( \pm 7$ anos), acreditou-se que boa parte dos nutrientes aportados pela adubação e pelo manejo dos resíduos já foi absorvida pelas plantas, resultando em decréscimo nos teores de nutrientes disponíveis no solo.

A manutenção de todos os resíduos florestais na área, após a colheita da madeira do primeiro ciclo (tratamento 2), resultou em aumento de $36,6 \%$ (71,7 $\mathrm{m}^{3} \mathrm{ha}^{-1}$ ) no volume de madeira produzido, quando comparado ao tratamento 1 , em que houve remoção de todos os resíduos vegetais, após a colheita florestal (Figura 1). A remoção desses resíduos resultou na exportação de grandes quantidades de nutrientes do talhão, que, se não forem repostos em quantidades adequadas pela adubação, podem comprometer a produtividade do eucalipto. Apenas a adubação de 
Quadro 5. Características químicas e granulometria do solo, 83 meses após a aplicação dos tratamentos

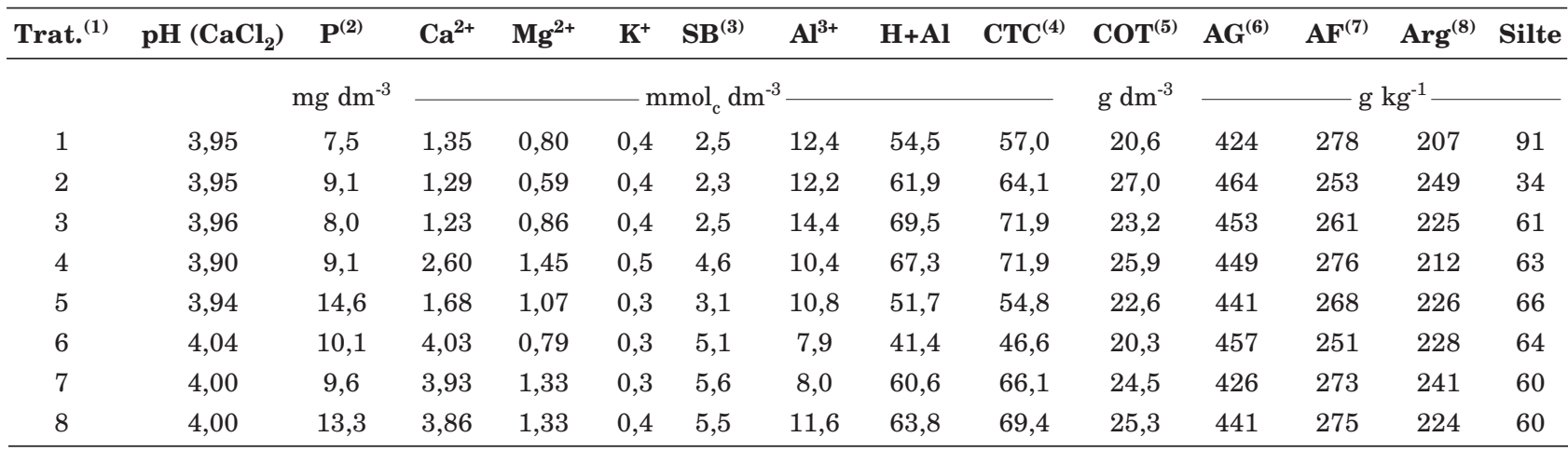

(1) 1: Todo resíduo da colheita retirado, preparo do solo com subsolador de três hastes, adubação de plantio com $200 \mathrm{~kg}$ ha-1 de $\mathrm{N}$ P-K (06-26-13); 2: Todo resíduo da colheita mantido na área, preparo do solo com subsolador de três hastes, adubação de plantio com $200 \mathrm{~kg} \mathrm{ha}^{-1}$ N-P-K (06-26-13); 3: Remoção dos galhos > $3 \mathrm{~cm}$ e da casca, preparo do solo com subsolador de três hastes, adubação de plantio com $200 \mathrm{~kg} \mathrm{ha}^{-1} \mathrm{~N}-\mathrm{P}-\mathrm{K}$ (06-26-13); 4: Remoção dos galhos $>3 \mathrm{~cm}$ e da casca, preparo do solo com subsolador de três hastes, adubação de plantio com $200 \mathrm{~kg} \mathrm{ha}^{-1} \mathrm{~N}-\mathrm{P}-\mathrm{K}(06-26-13)+7,5 \mathrm{Mg} \mathrm{ha}^{-1}$ de resíduo de celulose $+2,0 \mathrm{Mg}$ ha-1 de cinzas; 5: Remoção dos galhos $>3 \mathrm{~cm}$ e da casca, preparo do solo com subsolador de uma haste, adubação de plantio com $200 \mathrm{~kg}$ ha ${ }^{-1} \mathrm{~N}$ P-K (06-26-13) + 7,5 Mg ha-1 de resíduo de celulose + 2,0 $\mathrm{Mg} \mathrm{ha}^{-1}$ de cinzas; 6 : Remoção dos galhos > $3 \mathrm{~cm}$ e da casca, preparo do solo com subsolador de três hastes, adubação de plantio com $200 \mathrm{~kg} \mathrm{ha}^{-1} \mathrm{~N}-\mathrm{P}-\mathrm{K}(06-26-13)+15,0 \mathrm{Mg}^{-1}$ de resíduo de celulose + 4,0 Mg ha ${ }^{-1}$ de cinzas; 7: Remoção dos galhos $>3 \mathrm{~cm}$ e da casca, preparo do solo com subsolador de uma haste, adubação de plantio com $200 \mathrm{~kg} \mathrm{ha}^{-1} \mathrm{~N}-\mathrm{P}-\mathrm{K}(06-26-13)+15,0 \mathrm{Mg} \mathrm{ha}^{-1}$ de resíduo de celulose + 4,0 $\mathrm{Mg} \mathrm{ha}^{-1}$ de cinzas; e 8: Todo resíduo da colheita retirado, preparo do solo com subsolador de três hastes, adubação de plantio com $200 \mathrm{~kg} \mathrm{ha}^{-1} \mathrm{~N}-\mathrm{P}-\mathrm{K}(06-26-13)+15,0 \mathrm{Mg}$ ha ${ }^{-1}$ de resíduo de celulose $+4,0 \mathrm{Mg}$ ha $^{-1}$ de cinzas. ${ }^{(2)}$ Extrator Resina de troca aniônica; ${ }^{(3)}$ Soma de bases; ${ }^{(4)}$ Capacidade de troca catiônica; ${ }^{(5)}$ Carbono orgânico total; ${ }^{(6)}$ Areia grossa; ${ }^{(7)}$ Areia fina; ${ }^{(8)}$ Argila.

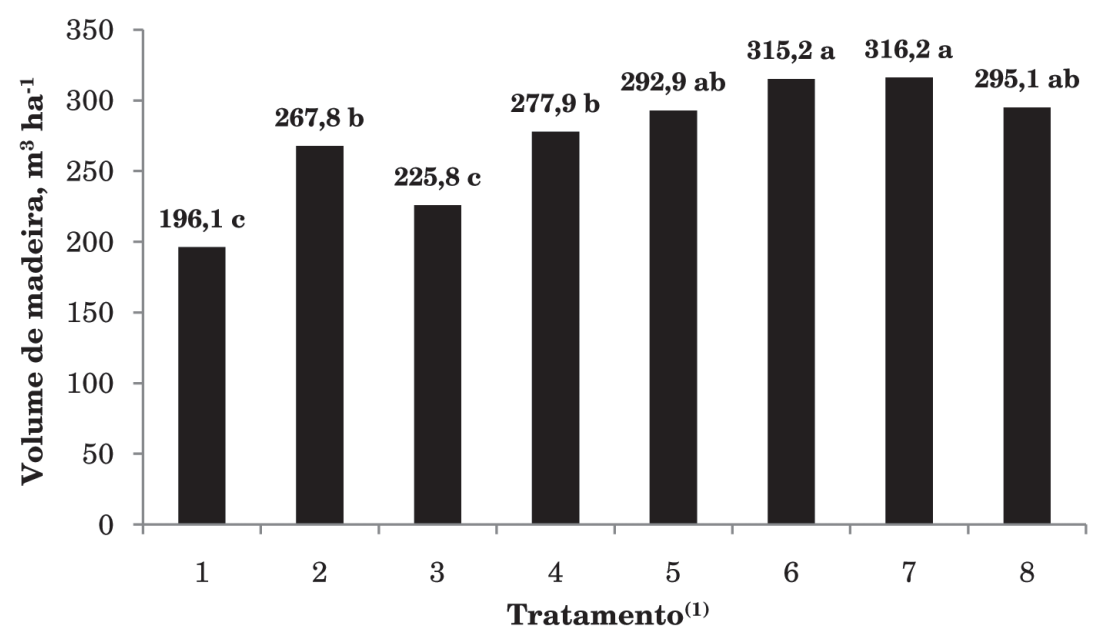

Figura 1. Volume médio de madeira de eucalipto aos 83 meses de idade para os diferentes tratamentos em estudo. CV $(\%)=9,1$. Médias seguidas pela mesma letra não diferem entre si pelo teste Tukey a $5 \%$. (1) 1: Todo resíduo da colheita retirado, preparo do solo com subsolador de três hastes, adubação de plantio com $200 \mathrm{~kg} \mathrm{ha}^{-1}$ de N-P-K (06-26-13); 2: Todo resíduo da colheita mantido na área, preparo do solo com subsolador de três hastes, adubação de plantio com $200 \mathrm{~kg} \mathrm{ha}^{-1}$ N-P-K (06-26-13); 3: Remoção dos galhos $>3 \mathrm{~cm}$ e da casca, preparo do solo com subsolador de três hastes, adubação de plantio com $200 \mathrm{~kg} \mathrm{ha}^{-1} \mathrm{~N}$ P-K (06-26-13); 4: Remoção dos galhos $>3 \mathrm{~cm}$ e da casca, preparo do solo com subsolador de três hastes, adubação de plantio com $200 \mathrm{~kg}_{\text {ha-1 }}$ N-P-K (06-26-13) + 7,5 $\mathrm{Mg}$ ha-1 de resíduo de celulose + 2,0 Mg ha-1 de cinzas; 5: Remoção dos galhos $>3 \mathrm{~cm}$ e da casca, preparo do solo com subsolador de uma haste, adubação de plantio com $200 \mathrm{~kg} \mathrm{ha}^{-1}$ N-P-K (06-26-13) + 7,5 $\mathrm{Mg} \mathrm{ha}^{-1}$ de resíduo de celulose + 2,0 Mg ha-1 de cinzas; 6: Remoção dos galhos $>3 \mathrm{~cm}$ e da casca, preparo do solo com subsolador de três hastes, adubação de plantio com $200 \mathrm{~kg} \mathrm{ha}^{-1} \mathrm{~N}-\mathrm{P}-\mathrm{K}(06-26-13)+15,0 \mathrm{Mg}^{-1}$ de resíduo de celulose + 4,0 Mg ha-1 de cinzas; 7: Remoção dos galhos $>3 \mathrm{~cm}$ e da casca, preparo do solo com subsolador de uma haste, adubação de plantio com 200 kg ha-1 N-P-K (06-26-13) + 15,0 Mg ha-1 de resíduo de celulose + 4,0 $\mathrm{Mg}_{\text {ha-1 }}$ de cinzas; e 8: Todo resíduo da colheita retirado, preparo do solo com subsolador de três hastes, adubação de plantio com $200 \mathbf{~ k g ~ h a}^{-1} \mathrm{~N}$ P-K (06-26-13) + 15,0 Mg ha-1 de resíduo de celulose + 4,0 Mg ha-1 de cinzas. 
plantio (200 kg ha-1 N-P-K 06-26-13) não foi suficiente para suprir a demanda nutricional do eucalipto, resultando em decréscimo da produtividade de madeira. Com isso, a remoção dos resíduos vegetais da área pela colheita florestal implicou em maior dependência da quantidade de nutrientes a ser aplicado por fertilizantes, resultando na elevação do custo da adubação.

Neste estudo, a remoção do resíduo vegetal decorrente da colheita da madeira exportou o correspondente a 266, 29, 164, 177 e $38 \mathrm{~kg} \mathrm{ha}^{-1} \mathrm{de} \mathrm{N}$, $\mathrm{P}, \mathrm{K}, \mathrm{Ca}$ e $\mathrm{Mg}$, respectivamente (Quadro 3). Além do aspecto nutricional, a remoção de todos os resíduos vegetais após a colheita da madeira expõe o solo ao impacto direto das gotas da chuva, desencadeando o processo erosivo (Martins, 2005), culminando em algumas situações na perda da camada superficial do solo. Entretanto, a manutenção dos resíduos da colheita aumenta o conteúdo de água e favorece o suprimento de nutrientes via mineralização ao longo do tempo (Gonçalves, 2002). Além disso, o acúmulo de resíduo da colheita na superfície do solo constitui em fonte de energia para os organismos que participam da ciclagem biogeoquímica (Kiehl, 1985). Em razão da textura franco argiloarenosa e do teor moderado de matéria orgânica, a quantidade de água disponível é limitada. A manutenção dos resíduos da colheita na superfície do solo resultou em aumento de quase $50 \%$ na quantidade de água disponível no horizonte superficial do solo $(0-10 \mathrm{~cm})$; sob esse mesmo experimento quando as plantas apresentavam 48 meses de idade (Dedecek et al., 2007). Possivelmente, essa maior disponibilidade de água no solo, medida aos 48 meses de idade, tem reflexo na produtividade de madeira de eucalipto aos 83 meses de idade, neste trabalho.

Ao revisarem diversos trabalhos referentes ao impacto da colheita florestal nos estoques de $\mathrm{C}$ do solo, Johnson \& Curtis (2001) concluíram que a colheita apenas do tronco das árvores, mantendo-se os demais resíduos na área, após a colheita, acarretou incremento de $18 \%$ no C orgânico do solo, enquanto a colheita da árvore inteira com os resíduos levou à redução de $6 \%$ no C orgânico do solo. Considerando que neste estudo o eucalipto encontrou-se em segundo ciclo e que a matéria orgânica do solo foi constituída por vários compartimentos com diferentes tempos de ciclagem em que, nas condições tropicais, a fração mais estável (substâncias húmicas) é, quantitativamente, dominante, a determinação direta das perdas e dos ganhos da matéria orgânica do solo pelo manejo do resíduo da colheita adotado na maioria dos tratamentos pode não ser facilmente quantificada em curto intervalo de tempo (Haynes, 1999).

A remoção da casca e dos galhos com diâmetro superior a $3,0 \mathrm{~cm}$ (tratamento 3 ) resultou em $42,0 \mathrm{~m}^{3} \mathrm{ha}^{-1}$ de madeira a menos que o tratamento 2 , com a manutenção de todos os resíduos vegetais na área (Figura 1), o que pode comprometer a sustentabilidade da produção florestal no longo prazo.
Neste trabalho, os tratamentos não receberam adubações de cobertura, prática comumente realizada pelas empresas florestais, fato que pode ter potencializado a redução na produção de madeira, quando da remoção da casca e dos galhos. A casca do eucalipto é o segundo componente das árvores que mais estoca C, depois da madeira (Wink, 2009). Além disso, essa casca é excelente fonte de nutrientes e contribui para diminuir a compactação do solo, decorrente da ação dos implementos florestais. Avaliando o efeito da compactação pelo tráfego do Forwarder em três condições de disposição de resíduo florestal na superfície de dois Latossolos (galhada, galhada + casca, solo sem resíduo) na região do Vale do Rio Doce, MG, Silva et al. (2007) observaram que o resíduo (galhada + casca) na superfície do solo foi mais eficiente em atenuar a compactação desse, decorrente do tráfego do Forwarder. O solo sem resíduo na superfície apresentou a maior compactação decorrente do tráfego do Forwarder, o que pode comprometer o crescimento radicular das plantas e, consequentemente, a absorção de água e nutrientes. A disposição de resíduos florestais na superfície do solo constitui importante alternativa para minimizar o impacto do tráfego na estrutura do solo, sob exploração florestal (Seixas et al., 1998). A disposição dos resíduos na superfície do solo atua distribuindo as pressões aplicadas, de tal maneira a evitar que a capacidade de suporte de carga do solo seja superada, o que reduziria o risco da compactação e a formação de sulcos pelos rodados das máquinas (McMahon \& Evanson, 1994).

Não houve diferença de volume de madeira entre o preparo do solo realizado com o subsolador de uma haste (tratamento 6) e o de três hastes (tratamento 7) (Figura 1). Com o aumento da idade do povoamento de eucalipto (83 meses), o efeito da subsolagem tornase insignificante, provavelmente em razão da reconsolidação do solo, que pode ser influenciada pela dinâmica da água no espaço poroso inter e intraagregados, assim como pela quantidade de água que infiltra nele (Busscher et al., 2002). Além disso, o fechamento das copas das árvores reduz o impacto da água da chuva na superfície do solo, possibilitando drenagem mais lenta da água no perfil do solo e maior disponibilidade de água para as plantas. Resultado oposto foi observado por Dedecek et al. (2007), ao avaliarem esse mesmo experimento no quarto ano após o plantio. Esses autores observaram que o crescimento do eucalipto foi maior quando o preparo do solo foi feito com o subsolador de uma haste. A diferença de crescimento das plantas aos 48 meses de idade justificou-se em termos de disponibilidade de água no solo, onde o preparo dele em faixas mais largas (subsolador de três hastes) propiciou maiores perdas da água da chuva por drenagem profunda, pelo aumento da porosidade de aeração do solo.

A aplicação de 7,5 $\mathrm{Mg} \mathrm{ha}^{-1}$ de resíduo celulósico + $2,0 \mathrm{Mg} \mathrm{ha}^{-1}$ de cinzas de madeira, além dos $200 \mathrm{~kg} \mathrm{ha}^{-1}$ de N-P-K (6-26-13) (tratamento 4), resultou em rendimentos semelhantes ao da manutenção de todos 
os resíduos vegetais na área, após a colheita de madeira (tratamento 2) (Figura 1). No entanto, a manutenção de parte dos resíduos vegetais na área após a colheita (folhas, ponteiras, serapilheira e galhos inferiores a $3,0 \mathrm{~cm}$ de diâmetro) e a aplicação de $15,0 \mathrm{Mg} \mathrm{ha}^{-1}$ de resíduo de celulose $+4,0 \mathrm{Mg} \mathrm{ha}^{-1}$ de cinzas de madeira, além dos $200 \mathrm{~kg} \mathrm{ha}^{-1}$ de N-P-K (6-26-13) (tratamento 6), resultaram em maiores rendimentos, em relação ao tratamento 2 , com a manutenção de todos os resíduos vegetais na área, após a colheita da madeira (Figura 1). Quantidades expressivas de nutrientes são fornecidas às plantas por meio do resíduo celulósico e das cinzas (Quadro 4), que também proporcionam aumento na retenção de água na superfície do solo, favorecendo o estabelecimento e a manutenção do povoamento de eucalipto (Guerrini \& Moro, 1994). Avaliando a influência das cinzas de biomassa florestal nos atributos de solos ácidos do planalto catarinense e em plantas de $E$. viminalis, Silva et al. (2009) observaram que as doses avaliadas não alteraram os atributos físicos dos solos nem o $\mathrm{pH}$, porém reduziu a saturação por $\mathrm{Al}$, elevou os teores de $\mathrm{K}, \mathrm{P}, \mathrm{Ca}, \mathrm{Mg}$ e soma de bases dos solos. Ademais, a cinza elevou o teor de $\mathrm{K}$ no tecido da parte aérea de plantas de eucalipto cultivadas, após 70 dias de cultivo. Durante a queima de biomassa florestal é produzida a cinza que apresenta em sua composição compostos orgânicos e inorgânicos, que podem ter efeitos favoráveis para a planta, especialmente em solos com elevada deficiência nutricional (Jordan et al., 2002).

Os resíduos celulósicos têm potencial para uso em solos com plantios florestais para repor os nutrientes extraídos pelas árvores, pelo fato de apresentarem cátions como $\mathrm{K}, \mathrm{Ca}$ e $\mathrm{Mg}$, além de $\mathrm{P}$, e uma relação C/N de 30/1 (Quadro 4), que possibilita rápida decomposição. Esses resíduos ao serem aplicados no solo aumentam a taxa de decomposição de serapilheira (Ferreira et al., 1995). Nesse mesmo experimento, durante o período de 11 meses, dois anos após o plantio, Bellote et al. (2008) avaliaram mensalmente o estado nutricional das plantas, observando que não houve correlação entre os teores de N, P e K nas folhas, com as quantidades desses nutrientes aplicados pelos resíduos da indústria de celulose. Os teores de $\mathrm{N}$ e $\mathrm{P}$ estavam na faixa considerada adequada para o eucalipto, enquanto o $\mathrm{K}$ estava abaixo. Para o $\mathrm{Ca}$, observou-se que o teor desse nutriente nas folhas foi maior no tratamento com aplicação de resíduo industrial (resíduo de celulose e cinzas), quando comparado aos demais tratamentos; o tratamento com remoção total dos resíduos apresentou menor teor de Ca nas folhas, evidenciando a estreita correlação do Ca nas folhas com o Ca aplicado pelos resíduos, ficando claro que os resíduos da colheita florestal são fontes de Ca para as plantas e, dessa maneira, devem ser mantidos na área após a colheita. Na impossibilidade dessa prática, a adição de resíduos da indústria de celulose (resíduo de celulose e cinzas) deve ser considerada como alternativa de fonte desse nutriente para as plantas, em virtude da quantidade de Ca na sua constituição. Os menores teores de $\mathrm{Mg}$ foliar foram observados no tratamento em que houve a remoção de todo o resíduo da colheita e adição de resíduo industrial. $\mathrm{O} \mathrm{Mg}$ foliar apresentou correlação positiva com o $\mathrm{Mg}$ adicionado ao solo, exceto quando se aplicou resíduo de celulose e cinza. Possivelmente, a elevada quantidade de Ca aplicado pelo resíduo industrial pode ter inibido por competição a absorção de $\mathrm{Mg}$ (Marschner, 1995). Ressalta-se a importância da determinação da composição química do resíduo de celulose e do solo e seu acompanhamento ao longo do tempo, pois quando aplicado em quantidades consideradas inadequadas pode prejudicar o solo e o meio ambiente pelo desbalanço de nutrientes. Além disso, concentrações mais elevadas de Ca no resíduo celulósico devem ser corrigidas com aplicações de Ke $\mathrm{Mg}$, para evitar futuramente desequilíbrio nutricionais nas árvores.

Em relação às quantidades de nutrientes aplicadas nos diferentes tratamentos (Quadro 3), houve correlação significativa entre as quantidades de Ca e $\mathrm{Mg}$ adicionados pelos tratamentos e pelo rendimento de madeira (Figura 2a). De acordo com Mengel \& Kirkby (2000), o Ca beneficia vários processos

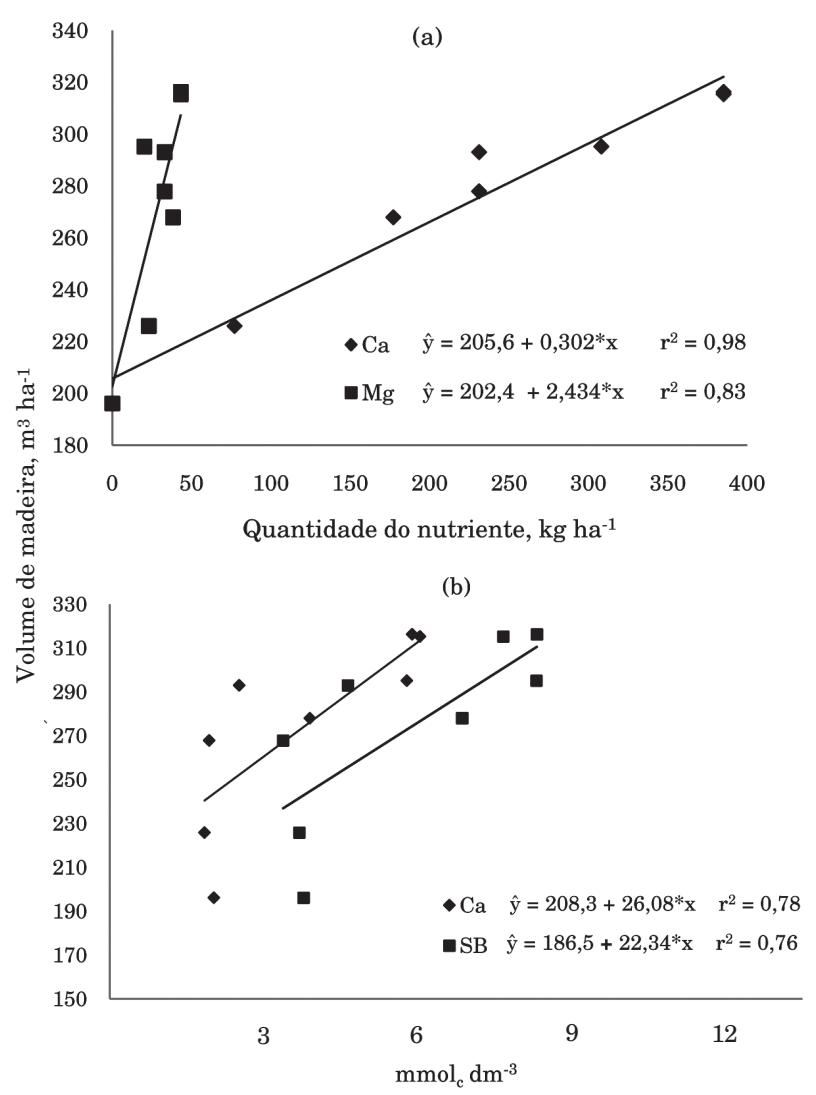

Figura 2. Volume de madeira de eucalipto aos 83 meses de idade: (a) em função das quantidades de $\mathrm{Ca}$ e $\mathrm{Mg}$ aplicadas nos diferentes tratamentos; e (b) do teor de $\mathrm{Ca}^{2+}$ e da soma de bases (SB) no solo. *: todos os modelos são significativos a $5 \%$. 
metabólicos nas plantas, como a formação da parede celular e da lamela média, além de ativar diversos sistemas enzimáticos, contribuindo para o bom desenvolvimento das plantas. Dentre os nutrientes acumulados na biomassa total do eucalipto, o Ca e Mg são o primeiro e o quarto, respectivamente, na ordem decrescente de acúmulo (Santana et al., 2008). As atividades de colheita que removam a madeira juntamente com a casca exportam grande quantidade desse nutriente, devendo esse ser reposto para que os próximos ciclos não sejam comprometidos quanto à produtividade (Foelkel, 2009). Houve também correlação significativa entre os teores de $\mathrm{Ca}^{2+}$ no solo, soma de bases e volume de madeira produzido (Figura 2b). Maiores rendimentos de madeira foram observados nos tratamentos em que a quantidade de Ca no solo e a soma de bases foram mais elevadas.

\section{CONCLUSÕES}

1. A adubação e a manutenção dos resíduos da colheita florestal elevam os teores de $\mathrm{Ca}^{2+}{\mathrm{e} \mathrm{Mg}^{2+}}^{2+}$ disponível no solo.

2. O preparo do solo com subsolador de uma haste não difere com o de três hastes, quanto ao rendimento de madeira aos 83 meses de idade.

3. A adubação com resíduo de celulose e cinzas de madeira favorece a manutenção e, ou,o aumento do rendimento de madeira.

\section{AGRADECIMENTOS}

Aos técnicos Jair Gabriel e José Teixeira, pela adequada manutenção do experimento.

\section{LITERATURA CITADA}

BARROS, N.F. \& NOVAIS, R.F. Eucalipto. In: RIBEIRO, A.C.; GUIMARÃES, P.T.G. \& ALVAREZ V., V.H.,eds. Recomendações para o uso de corretivos e fertilizantes em Minas Gerais: $5^{\text {a }}$ aproximação. Viçosa, MG, CFSEMG/ UFV, 1999. p.303-305.

BARROS, N.F. \& NOVAIS, R.F. Relação solo-eucalipto. Viçosa, MG, Folha de Viçosa, 1990. 330p.

BELLOTE, A.F.J.; DEDECEK, R.A. \& SILVA, H.D. Nutrientes minerais, biomassa e deposição de serapilheira em plantio de Eucalyptus com diferentes sistemas de manejo de resíduos florestais. Pesq. Flor. Bras., 56:31-41, 2008.

BELLOTE, A.F.J.; SILVA, H.D.; FERREIRA, C.A. \& ANDRADE, G.C. Resíduos da indústria de celulose em plantios florestais. Bol. Pesq. Flor., 37:99-106, 1998.
BUSSCHER, W.J.; BAUER, P.J. \& FREDERICK, J.R. Recompaction of a coastal loamy sand after deep tillage as a function of subsequent cumulative rainfall. Soil Till. Res., 68:49-57, 2002.

ClAESSEN, M.E.C.; BARRETO, W.O.; PAULA, J.L. \& DUARTE, M.N., orgs. Manual de métodos de análise de solo. 2.ed. Rio de Janeiro, Empresa Brasileira de Pesquisa Agropecuária, 1997. 212p.

DEDECEK, R.A.; BELLOTE, A.F.J. \& MENEGOL, O. Influence of residue management and soil tillage on second rotation Eucalyptus growth. Sci. For., 74:9-18, 2007.

EMPRESA BRASILEIRA DE PESQUISA AGROPECUÁRIA EMBRAPA. Centro Nacional de Pesquisa de Solos. Sistema brasileiro de classificação de solos. Rio de Janeiro, 1999. $412 \mathrm{p}$

FERREIRA, C.A.; SILVA, H.D.; BELLOTE, A.F.J. \& ANDRADE, G.C. Efecto de la aplicacion de ceniza y residuo de celulosa en la descomposición y liberación de nutrientes de la hojarasca en plantaciones de Eucalyptus grandis. Bosque,16:101-104, 1995.

FOELKEL, C. Minerais e nutrientes das árvores dos eucaliptos: Aspectos ambientais, fisiológicos, silviculturais e industriais a cerca dos elementos inorgânicos presentes nas árvores. Disponível em: <http:// w w w . e u c a l y ptu s. com.br/capitulos/ capitulo_minerais.pdf>. Acesso em: 10 set. de 2009.

GONÇALVES, J.L.M. Conservação do solo. In: GONÇALVES, J.L.M. \& STAPE, J.L., eds. Conservação e cultivo de solos para plantações florestais. Piracicaba, IPEP, 2002. p.47129.

GUERRINI, I.A. \& MORO, L. Influência da aplicação de resíduos industriais de fábrica de celulose e papel em plantios de eucalipto: Efeitos no solo e na planta. In: GUERRINI, I.A.; BELLOTE, A.F.J. \& BÜLL, L.T., ed. SEMINÁRIO SOBRE USO DE RESÍDUOS INDUSTRIAIS E URBANOS EM FLORESTAS,Botucatu, 1994. Anais.. Botucatu, FCA/UNESP, 1994. p.189-215.

HAKAMADA, R.E.; LIMA, A.M.N.; SILVA, L.F.; PAES, F.A.S.V. \& TAKAHASHI, S.S. Efeito da aplicação contínua de resíduos celulósicos nas características físico-químicas do solo sob cultivo de Eucalyptus grandis $x$ Eucalyptus urophylla. In: CONGRESSO BRASILEIRO DE CIÊNCIA DO SOLO, 32., Fortaleza, 2009. Anais... Fortaleza, Universidade Federal do Ceará, 2009. CD ROM

HAYNES, R.J. Labile organic matter fractions and aggregate stability under short-term, grass-based leys. Soil Biol. Biochem., 31:1821-1830, 1999.

JOHNSON, D.W. \& CURTIS, P.S. Effects of Forest management on soil $\mathrm{C}$ and $\mathrm{N}$ storage: meta analysis. For. Ecol. Manage, 140:227-238, 2001.

JORDAN, M.; SÁNCHEZ, M.A.; PADILLA, L; CÉSPEDES, R.; OSSES, M. \& GONZÁLEZ, B. Kraft mill residues effects on Monterey Pine growth and soil microbial activity. Environ. Qual., 31:1004-1009, 2002.

KIEHL, E.J. Fertilizantes orgânicos. São Paulo, Agronômica Ceres, 1985. 492p. 
LEITE, F.P.; SILVA, I.R.; NOVAIS, R.F.; BARROS, N.F. \& NEVES, J.C.L. Alterations of soil chemical properties by eucalyptus cultivation in five regions in the Rio Doce Valley. R. Bras. Ci. Solo, 34:821-831, 2010.

MARSCHNER, H. Mineral nutrition of higher plants. 2.ed. London, Academic Press, 1995. 889p.

MARTINS, S.G. Erosão hídrica em povoamento de eucalipto sobre solos coesos nos Tabuleiros Costeiros, ES. Lavras, Universidade Federal de Lavras, 2005. 106p. (Tese de Doutorado)

McMAHON, S. \& EVANSON, T. The effect of slash cover in reducing soil compaction resulting from vehicle passage. Logging Ind. Res. Org. Report, 9:1-8, 1994.

MENGEL, K. \& KIRKBY, E.A.Principios de nutrición vegetal. Basel, International Potash Institute, 2000. 692p.

NOVAIS, R.F. \& SMYTH, T.J.Fósforo em solo e planta em condições tropicais. Viçosa, MG, Universidade Federal de Viçosa, 1999. 399p.

PAULA, R.R.; PEREIRA, M.G.; SANTIAGO, R.R. \& AMORIM, H.B. Propriedades edáficas e desenvolvimento de eucalipto em topossequência na Flona Mário Xavier - RJ. Flor. Amb., 16:344-351, 2012.

RAIJ, B.van; CANTARELLA, H.; QUAGGIO, J.A. \& FURLANI, A.M.C. Recomendação de adubação e calagem para o Estado de São Paulo. 2.ed. Campinas, Instituto Agronômico \& Fundação IAC, 1996. 285p. (Boletim Técnico, 100)

RIBEIRO, A.C.; GUIMARÃES, P.T.G. \& ALVAREZ V., V.H. Recomendações para o uso de corretivos e fertilizantes em Minas Gerais: $5^{\text {a }}$ aproximação. Viçosa, MG, CFSEMG/ UFV, 1999. 359p.
SANCHES, O.A.; YONEZAWA, J.T. \& ZEN, S. Evolução do cultivo mínimo em reflorestamentos na Cia. Suzano de papel e celulose. In: SEMINÁRIO SOBRE CULTIVO MÍNIMO DO SOLO EM FLORESTAS, 1.,Curitiba, 1995. Anais... Curitiba, CNPFloresta, IPEF, UNESP, SIF, FUPEF, 1995. p.140-147.

SANTANA, R.C.; BARROS, N.F.; NOVAIS, R.F.; LEITE, H.G. \& COMERFORD, N.B. Alocação de nutrientes em plantios de eucalipto no Brasil. R. Bras. Ci. Solo, 32:2723-2733, 2008.

SEIXAS, F.; OLIVEIRA JÚNIOR, E.D. \& SOUZA, C.R. Efeito da camada de resíduos florestais na compactação do solo causada pelo transporte primário da madeira. Sci. For., 54:9-16, 1998.

SILVA, A.R.; DIAS JÚNIOR, M.S \& LEITE, F.P. Camada de resíduos florestais e pressão de preconsolidação de dois Latossolos. Pesq. Agropec. Bras., 42:89-93, 2007.

SILVA, F.R.; ALBUQUERQUE, J.A.; GATIBONI, L.C. \& MARANGONI, J.M. Cinza de biomassa florestal: Alterações nos atributos de solos ácidos do Planalto Catarinense e em plantas de eucalipto. Sci. Agríc., 10:475$482,2009$.

SOUSA, D.M.G.; MIRANDA, L.N. \& OLIVEIRA, S.A. Acidez do solo e sua correção. In: NOVAIS, R.F.; ALVAREZ V., V.H.; BARROS, N.F.; FONTES, R.L.F.; CANTARUTTI, R.B. \& NEVES, J.C.L., eds. Fertilidade do solo. Viçosa, MG, Sociedade Brasileira de Ciência do Solo, 2007. p.205-274.

STATSOFT INCORPORATION. Statistica (data analysis software system), version 7.0.Tulsa. Disponível em: <http:/ /www.statsoft.com>. Acesso em: 8 Nov. 2008.

WINK, C. Estoque de carbono em plantações de Eucalyptus sp implantados em campo nativo. Santa Maria, Universidade Federal de Santa Maria, 2009. 132p. 